\title{
Optimal Decisions of a Supply Chain with Two Risk-Averse and Competing Retailers under Random Demand
}

\author{
Yu-Shuang Liu \\ School of Mathematics and Physics, Qingdao University of Science and Technology, Qingdao 266061, China \\ Correspondence should be addressed to Yu-Shuang Liu; qustlys@126.com
}

Received 5 July 2013; Revised 17 September 2013; Accepted 18 September 2013

Academic Editor: Matjaz Perc

Copyright ( 2013 Yu-Shuang Liu. This is an open access article distributed under the Creative Commons Attribution License, which permits unrestricted use, distribution, and reproduction in any medium, provided the original work is properly cited.

\begin{abstract}
This paper investigates the optimal decisions in a decentralized supply chain consisting of one manufacturer and two competing retailers who face price-sensitive and stochastic demand. The retailers are risk averse with conditional value at risk (CVaR) as their risk measure, and the manufacturer is a risk-neutral agent. We construct manufacturer-Stackelberg games with retailers, who engage in horizontal price competition. For the multiplicative demand model and expected demand as an exponential function of both prices, we show that there exists the optimal pricing-ordering joint decision uniquely. We then explore the influence of the price sensitivity, risk aversion, and retail competition on optimal decisions and channel efficiency. The results show that retail competition contributes to manufacturer and improves channel efficiency of the decentralized supply chain. When the retailers are more risk averse, the channel efficiency becomes much lower. However, the level of retailers' risk aversion has no significant impact on the manufacturer's optimal wholesale price and retailer's optimal selling price.
\end{abstract}

\section{Introduction}

This paper characterizes a two-stage supply chain consisting of one manufacturer and two competing retailers in a single-period setting with price-sensitive random demand. Differing from the previous studies that mainly focus on riskneutral retailers, we examine risk-averse retailers engaged in horizontal price competition. Our objective is to obtain retailer's optimal pricing-ordering joint decision under the revenue-sharing (RS) contract offered by the manufacturer. Then, another objective is to investigate how the price sensitivity, the level of retail competition, and risk aversion affect the decentralized supply chain equilibrium and its efficiency, defined as the ratio of the aggregate profit of manufacturer and retailers in the decentralized and centralized chains.

In the classical newsvendor pricing model, the challenge is to determine jointly the price and the ordering quantity of a product when demand for the product is a function of the price. Therefore, the literature about price-sensitive newsvendor model try to answer two questions: (1) how to properly model the stochastic, price-dependent demand and (2) how to derive the optimal solutions for the newsvendor problem with price and ordering quantity as joint decisions. For the first question, the stochastic, price-dependent demand can be decomposed into two parts: the mean demand that is dependent on the price, and the stochastic factor is price independent. Both the additive and the multiplicative demand models serve as the two basic functional forms to incorporate price into the demand uncertainty [1]. Specifically, demand is defined as the sum of the expected demand and a random variable in the additive case; however, demand is the product of the expected demand and a positive random variable in the multiplicative case. Subsequent studies on the more general demand forms include Yao et al. [2], Kocabıyıkoğlu and Popescu [3], and Xu et al. [4]. For the second question, most literature tries to prove the objective function to be unimodal or quasiconcave, which guarantees the existence and uniqueness of the optimal solutions.

In a decentralized chain with two downstream members, Pan et al. [5] compare the channel performance of the RS contract with the price-only contract for two competing retailers. In their model, retail demand is linear in price under deterministic demand. In a stochastic demand environment, Yao et al. [6] examine the RS contract for coordinating 
a supply chain with one manufacturer and two competing retailers. The random demand model in [6] takes on an additive form, and the expected demand is a linear function of both retail prices. Adida and Ratisoontorn [7] investigate how competition among retailers influences the supply chain decisions and profits under different consignment arrangements, namely, a consignment price contract and a consignment contract with revenue sharing. However, in their model, the random demand takes on a multiplicative form, and the expected demand is an exponential function of both retail prices. In addition, Bernstein and Federgruen [8] consider one manufacturer and multiple retailers who compete by choosing their retail prices. They assume that the demand faced by each retailer is stochastic with a distribution that depends on the retail prices of all retailers.

The aforementioned studies focus on a risk-neutral setting in which the chain members' objectives are to maximize expected profit. When facing random demand, however, the downstream members will be more concerned with the risk associated with demand uncertainties. This inclusion of risk into decision making has drawn a lot of attention and is gaining increasing interest in supply chain studies. Eeckhoudt et al. [9] study the risk-averse newsboy problem. Agrawal and Seshadri [10] extend their framework to include, in addition, pricing decision and model risk aversion with the general utility function. Choi et al. [11] investigate the issues of channel coordination in a supply chain with agents having meanvariance objectives. Gan et al. [12] consider how a supply chain involving a risk-neutral supplier and a downside-riskaverse retailer can be coordinated with a supply contract. Originally introduced in financial risk management, conditional value at risk ( $\mathrm{CVaR})$ has emerged in recent years as one of the major risk criteria. By adopting $\mathrm{CVaR}$ as the decision criterion, Wu et al. [13] obtain closed-form solutions for the manufacturer's optimal ordering strategies, which characterize the explicit relationship between the manufacturer's risk attitude and his optimal decisions. Chen et al. [14] investigate the optimal policy of a risk-averse newsvendor who faces stochastic price-dependent demand and establish sufficient conditions for the uniqueness and existence of the optimal policy under CVaR.

The problem considered in this paper draws ideas from three research areas: (1) pricing-setting newsvendor problem, (2) retail competition, and (3) risk aversion. In this paper, we address these questions in the context of two-echelon supply chain with a single manufacturer selling homogeneous products through two competing retailers. The manufacturer and two retailers play, vertically, a Stackelberg game, with the manufacturer as the leader and the two retailers as followers. Horizontally, the two retailers play a Nash game; that is, they simultaneously decide their prices and stocking quantities. This paper, thus, introduces horizontal competition at the retailer level in addition to vertical competition between the manufacturer and the retailers. Two retailers take CVaR as their performance measure and obtain their optimal pricing and ordering decisions under the RS contract offered by the manufacturer. It can be shown that the RS contract cannot attain coordination in our setting. Hence, this paper does not address coordination issues. Instead, we concentrate on identifying some structural properties of optimal decisions when the competitive retail demand can be expressed in a specific multiplicative form. In particular,

(1) we provide a method of establishing the quasi-concavity of the pricing-ordering joint decision for riskaverse retailers under retail competition. Then we show that the existence and uniqueness of optimal decisions under reasonable regularity condition known as increasing failure rate (IFR);

(2) we prove that the equilibrium retail price and safety stock decrease with the price sensitivity and retail competition, whereas safety stock increases with the degree of risk aversion;

(3) we compare, through numerical studies, the influence of retail competition and risk aversion on the optimal decisions and channel efficiency.

Although there is limited research on risk-averse retailers under retail competition, the work of Hsieh and Lu [15] deserves special mention. They consider manufacturer's return policy in a two-stage supply chain with two riskaverse retailers and random demand. Each retailer's expected demand depends on three basic elements-the primary demand, store level factor, and competitive factor, as in Yao et al. [6]. Hsieh and Lu's model differs from ours in its assumption of demand in which the expected demand is a linear function and takes on an additive form. However, we adopt a multiplicative demand form and explicitly characterize the effect of price sensitivity and retail competition on the retailers' demand.

The rest of this paper is organized as follows. Section 2 describes the model. Section 3 gives the closed-form expressions for the equilibrium results and analyzes some properties of them. The computational experiments and the comparative results are presented in Section 4. Section 5 concludes the paper. In addition, the detailed proofs for all the lemmas and propositions are provided in the appendix.

\section{Preliminaries}

2.1. The Demand Model. Consider a two-stage distribution channel where one manufacturer sells homogeneous products to two risk-averse retailers, who compete in the final market by selling products to end customers. The retailers are indexed by $i \in\{1,2\}$ and $j=3-i$. The manufacturer produces at a unit cost $c_{m}$, and retailer $i$ incurs a unit processing cost $c_{i}$ for handling and selling products to consumers. The demand for the product at each retailer during a single selling season is price dependent and stochastic. To capture the randomness in the demand, a multiplicative demand scenario is widely used for studying price-setting newsvendor paradigms (see e.g., Petruzzi and Dada [1], Wang et al. [16], and Song et al. [17]). We thus assume the demand for the product at retailer $i$, denoted by $D_{i}(p)$, where $p=\left(p_{1}, p_{2}\right)$, as

$$
D_{i}(p)=y_{i}(p) \varepsilon
$$

The first part represents the deterministic component of demand at retailer $i$, capturing the economics of price 
competition between retailers. The second part denotes the randomness of demand, with a mean value of 1 , cumulative distribution function $F(\cdot)$ and probability density function $f(\cdot)$, that have support $[A, B]$ with $B>A \geq 0$. Similar to [1], we impose a mild restriction on $\varepsilon$ known as IFR. The IFR property is indeed satisfied by most of the distributions used in the previous literature.

Assumption 1 (see [18]). The demand distribution of $\varepsilon$ satisfies the IFR property: $h(x)=f(x) /[1-F(x)]$ is increasing in $x$.

In the absence of competition, an exponential expected demand function (also called log-linear) $y(p)=a e^{-b p}$, where $b$ is a price-sensitive parameter and $p$ is the retail price, has been adopted in $\mathrm{Ru}$ and Wang [19]. In order to capture retail competition, retailer $i$ 's expected demand decreases with its own price $p_{i}$ and increases with the opponent's price $p_{j}$. As retailers are more competitive, one retailer's sales are affected by the other retailer's price level. Here, we extend the expected demand function used in [19] as follows:

$$
y_{i}(p)=a e^{-b p_{i}+\gamma\left(p_{j}-p_{i}\right)}
$$

where $a>0$ is the primary demand for each retailer when both prices are set at zero, $b>0$ is each retailer's price sensitivity of demand, and $\gamma>0$ reflects their competition intensity. As $\gamma$ increases, the retailers are more substitutable in the sense that the demand of product would become more sensitive toward the relative price $\left(p_{j}-p_{i}\right)$, and therefore, the degree of retail competition is intensifying. In other words, there is no competition when $\gamma=0$. This function is the logarithm of a class of more general linear demand functions used in many previous studies (refer to Pan et al. [5], Tang and Yin [20], Chen and Roma [21], Choi [22], and Zhao and Atkins [23] for details). This type of retail competition model via demand dependency on the competitor's price is common to many studies in the operation management literature.

2.2. Performance Measure: CVaR. Rockafellar and Uryasev $[24,25]$ give the following equivalent definition, which is convenient for optimization,

$$
\mathrm{CVaR}_{\eta}(\pi(x, y))=\max _{v \in R}\left\{v+\frac{1}{\eta} \mathrm{E}[\min (\pi(x, y)-v, 0)]\right\},
$$

where $\mathrm{E}$ is the expectation operator and $\eta \in(0,1]$ reflects the degree of risk aversion for the retailer (the smaller $\eta$ is, the more risk averse the retailer is). We hereafter adopt the notations $\mathrm{CVaR}_{\eta}$ to underscore the dependence of $\mathrm{CVaR}$ on the confidence level $\eta$.

\section{Optimal Decisions of Retailers under the RS Contract}

Suppose that the manufacturer offers the same RS contract to retailers. Let $w$ be the per unit wholesale price and, in addition, $\phi$ the fraction of revenue the retailer keeps; so $1-\phi$ is the fraction the manufacturer earns. In this game, the manufacturer acts as a Stackelberg leader, and the two retailers act as followers. Horizontally, two retailers play a Nash game; that is, they simultaneously decide selling price $p_{i}$ to the customer and order quantity $q_{i}$ to be placed on the manufacturer.

\subsection{Retailer's Optimal Pricing-Ordering Joint Decision under} the CVaR Criterion. The stocking factor or safety stock is defined as $z_{i}=q_{i} / y_{i}(p)$, which is a measure of the deviation of the order quantity from the expected demand. Using $z_{i}$ as a decision variable instead of $q_{i}$, retailer $i$ 's profit function under a RS contract is

$$
\pi_{i}\left(p_{i}, z_{i}\right)=y_{i}(p)\left\{\left(\phi p_{i}-w-c_{i}\right) z_{i}-\phi p_{i}\left(z_{i}-x\right)^{+}\right\} .
$$

Substituting (4) into (3), the risk-averse retailer $i$ jointly determines retail price $p_{i}$ and stocking factor $z_{i}$ to maximize

$$
\begin{array}{r}
\pi_{i}\left(p_{i}, z_{i}, v_{i}\right)=v_{i}-\frac{1}{\eta_{i}} \int_{A}^{B}\left[v_{i}-y_{i}(p)\left(\phi p_{i}-w-c_{i}\right) z_{i}\right. \\
\left.+y_{i}(p) \phi p_{i}\left(z_{i}-x\right)^{+}\right]^{+} d F(x) .
\end{array}
$$

Firstly, the following two lemmas will be useful throughout this paper.

Lemma 2. Given $\eta_{i}$, the stocking factor $z_{i}$ of retailer $i$ must satisfy $F\left(z_{i}\right) \leq \eta_{i} \leq 1$.

The proof of Lemma 2, as well as the other main results, appears in the appendix. Lemma 2 implies that the more risk averse the retailer is, the smaller the range of $z_{i}$ is. Similar to [14], the $\eta$-failure rate $\left(\eta\right.$-FR) is $h_{\eta}(x)=f(x) /[\eta-F(x)]$ for all $x$, with $F(x)<\eta$ and $0<\eta<1$. If $F(x)<\eta$ and $h^{\prime}(x) \geq 0$, then $h_{\eta}(x)$ is also increasing in $x$. The following result is easy to verify and is thus given without a proof.

Lemma 3. For any $x>0$ and $F(x)<\eta$, if $h^{\prime}(x) \geq 0$, then $h_{\eta}^{\prime}(x)>0$.

From proof of Lemma 2 (see the appendix), it is shown that for any fixed $p_{i}$ and $z_{i}$, the optimal value of $v_{i}$ in the definition of CVaR satisfies

$$
v_{i}^{*}\left(p_{i}, z_{i}\right)=y_{i}(p)\left(\phi p_{i}-w-c_{i}\right) z_{i} .
$$

Accordingly, replacing $v_{i}^{*}$ of (6) into (5), the objective function then becomes a function with two variables:

$$
\begin{aligned}
\pi_{i}\left(p_{i}, z_{i}, v_{i}^{*}\right)= & y_{i}(p)\left(\phi p_{i}-w-c_{i}\right) z_{i} \\
& -\frac{1}{\eta_{i}} \int_{A}^{z_{i}} y_{i}(p) \phi p_{i}\left(z_{i}-x\right)^{+} d F(x) .
\end{aligned}
$$

Further, the objective function of the risk-averse retailer $i$ can be rewritten as

$$
\pi_{\eta_{i}}\left(p_{i}, z_{i}\right)=y_{i}(p)\left[\left(\phi p_{i}-w-c_{i}\right) z_{i}-\frac{1}{\eta_{i}} \phi p_{i} \Lambda\left(z_{i}\right)\right],
$$

where $\Lambda\left(z_{i}\right)=\int_{A}^{z_{i}}\left(z_{i}-y\right) f(y) d y$. 
To find risk-averse retailer $i$ 's best decisions, denoted by $\left(p_{i}^{*}, z_{i}^{*}\right)$, which maximize $\pi_{\eta_{i}}\left(p_{i}, z_{i}\right)$ of $(8)$ for a given $(w, \phi)$, we first find the optimal selling price $p_{i}^{*}\left(z_{i}\right)$ for any given $z_{i}$ and then maximize $\pi_{\eta_{i}}\left(p_{i}^{*}\left(z_{i}\right), z_{i}\right)$ with respect to $z_{i}$ to find the optimal stocking factor $z_{i}^{*}$. Proposition 4 is the key result of this section, as it provides sufficient conditions for the existence and uniqueness of the retailer $i$ 's optimal decisions and gives closed-form expressions of the optimal decisions at the same time.

Proposition 4. For a given $R S$ contract $(w, \phi)$ and any given stocking factor $z_{i}\left(A \leq z_{i}<F^{-1}\left(\eta_{i}\right)\right)$, the risk-averse retailer $i$ 's unique best response price $p_{i}^{*}\left(z_{i}\right)$ is given by

$$
p_{i}^{*}\left(z_{i}\right)=\frac{1}{b+\gamma}+\frac{w+c_{i}}{\phi} \frac{\eta_{i} z_{i}}{\eta_{i} z_{i}-\Lambda\left(z_{i}\right)} .
$$

If $h^{\prime}(\cdot) \geq 0$, then the retailer i's best response stocking factor $z_{i}^{*}$ that maximizes the retailer is objective function of (8) is uniquely determined as the solution of

$$
\frac{\eta_{i}}{\eta_{i}-F\left(z_{i}^{*}\right)}=\frac{\phi}{(b+\gamma)\left(w+c_{i}\right)}+\frac{\eta_{i} z_{i}^{*}}{\eta_{i} z_{i}^{*}-\Lambda\left(z_{i}^{*}\right)} .
$$

After we replace $z_{i}$ with $z_{i}^{*}$ in (9), the best response price of risk-averse retailer $i$ is

$$
p_{i}^{*}=\frac{1}{b+\gamma}+\frac{w+c_{i}}{\phi} \frac{\eta_{i} z_{i}^{*}}{\eta_{i} z_{i}^{*}-\Lambda\left(z_{i}^{*}\right)}
$$

In summary, for the decentralized channel under the RS contract, at equilibrium, the retailer $i$ chooses the corresponding stocking factor and retail price given by (10) and (11), respectively.

\subsection{Analysis of Equilibrium Decisions}

Lemma 5. For any given $z>0$ and $F(z)<\eta$, if $h^{\prime}(z) \geq 0$, let

$$
G(z)=\frac{\eta}{\eta-F(z)}-\frac{\eta z}{\eta z-\Lambda(z)}
$$

with $\Lambda(z)=\int_{A}^{z}(z-x) f(x) d x$; then, $G(z)$ is increasing in $z$.

With the help of Lemma 5, the following set of properties focus on how retail prices and safety stocks change with $b, \gamma$, and $\eta_{i}$.

Proposition 6. For any given stocking factor $z_{i} \in\left[A, F^{-1}\left(\eta_{i}\right)\right)$ and $h^{\prime}(\cdot) \geq 0$, then

(1) the equilibrium stocking factor $z_{i}^{*}$ decreases in $b$ and $\gamma$,

(2) the equilibrium retail price $p_{i}^{*}$ decreases in $b$ and $\gamma$,

(3) the equilibrium stocking factor $z_{i}^{*}$ increases in $\eta_{i}$.

Since the expected demand decreases when consumers become more sensitive to the retail price, retailer $i$ reduces stock and retail price to reduce the risk of excess inventory. The impact of $\gamma$ on the optimal decisions can be similarly explained. Therefore, $p_{i}^{*}$ and $z_{i}^{*}$ change with $b$ and $\gamma$ in the same way. Note that the smaller $\eta_{i}$ is, the more risk averse retailer $i$ is. The higher the degree of risk aversion, the fewer retailer $i$ orders. In the case of $p_{i}^{*}$, it is not immediately obvious how $p_{i}^{*}$ changes with $\eta_{i}$.

From (3) of Proposition $6, z_{i}^{*}$ is increasing in $\eta_{i}$, which means that the risk-averse retailer's best response stocking factor is usually smaller than that of the risk-neutral counterpart under RS contract. Therefore, RS contract cannot coordinate the supply chain with risk-averse retailers. So, we use the whole-sale price contract to explore how the price sensitivity of demand, the level of retail competition, and risk aversion influence the decision making of supply chain members and channel efficiency.

\section{Analysis of Supply Chain Performance}

4.1. Centralized and Decentralized Models. For a centralized channel, the decision is to simultaneously choose the selling price and safety stock with the objective to maximize channel $i$ 's expected profit. The channel $i(i=1,2)$ is composed by manufacturer and retailer $i$, whose expected profit can be written as

$$
\pi_{i}\left(p_{i}, z_{i}\right)=y_{i}(p)\left\{p_{i}\left[z_{i}-\Lambda\left(z_{i}\right)\right]-\left(c_{m}+c_{i}\right) z_{i}\right\} .
$$

Let $w=c_{m}$ and $\phi=\eta_{i}=1$ in Proposition 4 , we obtain $\left(\bar{p}_{i}, \bar{z}_{i}\right)$ that maximize (13).

Proposition 7. For a given stocking factor $z_{i}\left(A \leq z_{i} \leq B\right)$, channel i's unique best response price $\bar{p}_{i}\left(z_{i}\right)$ is given by

$$
\bar{p}_{i}\left(z_{i}\right)=\frac{1}{b+\gamma}+\frac{\left(c_{m}+c_{i}\right) z_{i}}{z_{i}-\Lambda\left(z_{i}\right)}
$$

If $h^{\prime}(\cdot) \geq 0$, then channel i's best response stocking factor $\bar{z}_{i}$ that maximizes channel i's profit is uniquely determined as the solution of

$$
\frac{1}{1-F\left(\bar{z}_{i}\right)}=\frac{1}{(b+\gamma)\left(c_{m}+c_{i}\right)}+\frac{\bar{z}_{i}}{\bar{z}_{i}-\Lambda\left(\bar{z}_{i}\right)} .
$$

In the same way, let $\phi=1$ in Proposition 4 , we thus give risk-averse retailer $i$ 's optimal decisions $\left(\widetilde{p}_{i}, \widetilde{z}_{i}\right)$ under the price-only contract.

Proposition 8. For a given wholesale price $w$ and any given stocking factor $z_{i}\left(A \leq z_{i}<F^{-1}\left(\eta_{i}\right)\right)$, the risk-averse retailer $i$ 's unique best response price $\widetilde{p}_{i}\left(z_{i}\right)$ is given by

$$
\tilde{p}_{i}\left(z_{i}\right)=\frac{1}{b+\gamma}+\frac{\left(w+c_{i}\right) \eta_{i} z_{i}}{\eta_{i} z_{i}-\Lambda\left(z_{i}\right)}
$$

If $h^{\prime}(\cdot) \geq 0$, then risk-averse retailer i's best response stocking factor $\widetilde{z}_{i}$ is uniquely determined as the solution of

$$
\frac{\eta_{i}}{\eta_{i}-F\left(\widetilde{z}_{i}\right)}=\frac{1}{(b+\gamma)\left(w+c_{i}\right)}+\frac{\eta_{i} \tilde{z}_{i}}{\eta_{i} \widetilde{z}_{i}-\Lambda\left(\widetilde{z}_{i}\right)} .
$$


4.2. Manufacturer's Wholesale Price Decision. Anticipating the retailers' reaction, the risk-natural manufacturer sets $w$ to maximize his expected profit under the price-only contract. Plugging the equilibrium selling price of (16) and stocking factor of (17) into the manufacturer's profit function, we have

$$
\pi_{M}(w)=\sum_{i=1}^{2} y_{i}(\widetilde{p})\left(w-c_{m}\right) \tilde{z}_{i}
$$

where $y_{i}(\tilde{p})=a e^{-b \widetilde{p}_{i}+\gamma\left(\widetilde{p}_{j}-\widetilde{p}_{i}\right)}$.

To find the optimal decision, we seek to maximize $\pi_{M}(w)$ of (18) over $w$. However, the manufacturer's expected profit after incorporating the retailers' best response functions would become too complex to be tractable. We therefore employ a numerical approach to find the manufacturer's and retailers' decisions at equilibrium.

4.3. Numerical Analysis. In this section, we explore optimal solutions of the price-only contract with two competing retailers in risk-averse setting, where $p_{i}$ and $z_{i}$ are the decision variables of retailers and $w$ is the decision variable of manufacturer. In Section 3.2, the effects of the risk aversion, price sensitivity, and retail competition on the retailers' selling and stocking decisions have been proved partly. We thus give numerical solutions that could not be obtained in previous sections. Specifically, we are interested in the issues that how the manufacturer's wholesale price decision, the retailer's pricing decision, and channel efficiency vary with respect to the risk-averse indicator $\eta$, the price sensitive factor $b$, and retail competition $\gamma$.

In order to properly evaluate the effect of $b$ on the equilibrium results, it is necessary to isolate it from other parameters (the risk aversion and retail competition) by keeping all these parameters constant. Moreover, we assume that the two retailers are symmetric in all parameters such as $c_{1}=c_{2}$ and $\eta_{1}=\eta_{2}$. The values of $c_{1}\left(\eta_{1}\right)$ and $c_{2}\left(\eta_{2}\right)$ that are equal to avoid introducing a cost (risk aversion) difference that could bias the effect of the parameter of interest. So, the two retailers' stocking factor (order quantities) and retail price decisions would be the same. Likewise, when we next explore the effect of risk aversion and retail competition on the equilibrium results only through parameter $\eta$ and $\gamma$, respectively.

The random perturbation on the demand, $\varepsilon$, is assumed to follow the uniform distribution on $[0,2]$ in order to ensure that the perturbation on the demand has a mean value of 1 . The related parameters are assumed as follows. $c_{m}=6, c_{1}=$ $c_{2}=2$, and $a=1000$ in $y_{i}(p)$ of (2). The parameters of $c_{m}$, $c_{i}$, and $a$ are fixed in our numerical study because we are not interested in the effect of these parameters.

For notational convenience, let $\widetilde{w}$ denote the manufacturer's optimal wholesale price, $\widetilde{z}=\widetilde{z}_{1}=\widetilde{z}_{2}$, and $\widetilde{p}=$ $\widetilde{p}_{1}=\widetilde{p}_{2}$ are the retailer's stocking factor and selling price at equilibrium under the wholesale price contract. $\tilde{\pi}_{M}$ and $\tilde{\pi}_{R}$ are the respective profits of the manufacturer and retailer given that the manufacturer charges $\widetilde{w}$ and the retailers set $\widetilde{z}$ and $\widetilde{p}(\widetilde{z}) . \widetilde{\pi}_{D}$ denotes the aggregate profit of the decentralized system; that is, $\tilde{\pi}_{D}=\tilde{\pi}_{M}+2 \tilde{\pi}_{R} \cdot \bar{z}_{1}=\bar{z}_{2}$ and $\bar{p}_{1}=\bar{p}_{2}$ denote stocking factor and selling price at equilibrium under the centralized channel, respectively. Let $\bar{\pi}_{I}$ denote the integrated channel profit at the optimal stocking level $\bar{z}$ and selling price $\bar{p}(\bar{z})$. The channel performance is represented by two aspects. The first is the division of realized profit between the retailers and the manufacturer, measured by the ratio of realized profits $2 \tilde{\pi}_{R} / \tilde{\pi}_{M}$. The second is the channel efficiency of the decentralized system, defined as the fraction $E_{f}=$ $\tilde{\pi}_{D} / \bar{\pi}_{I}$.

4.3.1. The Effect of the Price Sensitivity Factor b. In Table 1, the values of $\gamma$ and $\eta$ are fixed at $\gamma=1$ and $\eta=0.7,0.3$, respectively. Then, Table 1 summarizes, at equilibrium, the manufacturer's unit wholesale price, the retailers' stocking factor and selling price under decentralized and centralized decision models, the ratio of realized profits of supply chain members, and the channel efficiency, by varying the price sensitivity factor $b$.

The retailers' optimal stocking factor in the decentralized decision model is less than that in the centralized decision model, but the optimal selling price changes in an opposite way. These results are intuitive. The best response stocking factor and retail price decrease in $b$ regardless of the centralized and decentralized decision models, which is consistent with Proposition 6.

Considering the effect of $b$ on the manufacturer's decision variable, $\widetilde{w}$ decreases in $b$. Indeed, the manufacturer must decrease the wholesale price charged to the retailers when consumers are more sensitive to price changes. As a result, the retail price decreases in $b$, as seen in Table 1 . On the other hand, the trend of $2 \tilde{\pi}_{R} / \widetilde{\pi}_{M}$ increases in $b$, which indicates that the manufacturer's profit decreases in $b$ at a higher rate than the retailers' profits. Table 1 also shows that the higher $b$, the lower the channel efficiency.

\subsubsection{The Effect of the Risk Aversion and Retail Competition.} Table 2 summarizes the results by varying the level of risk aversion $\eta$ and retail competition $\gamma$ but keeping $b=2$. As we can see, the safety stock increases in $\eta$ with given $\gamma$, which is consistent with Proposition 6. At the same level of $b$ and $\gamma$, however, numerical results show that the manufacturer's unit wholesale price and the retailers' unit selling price are independent of $\eta$. The result is interesting. Further, when the price sensitivity factor $b$ keeps constant, the manufacturer's optimal wholesale price also keeps constant for any level of risk aversion and retail competition. Such a result implies that the wholesale price is mainly affected by the price sensitivity factor $b$. Likewise, no matter what the retailer's risk-averse attitude $\eta$ is, the ratio of $2 \tilde{\pi}_{R} / \widetilde{\pi}_{M}$ mainly keeps constant under the same level of $\gamma$. These peculiar conclusions should be noted under our specific demand model.

When we keep $b$ and $\eta$ constant, the best response stocking factor and retail price decrease in $\gamma$ regardless of the centralized and decentralized decision models, which is also consistent with Proposition 6. Under the same conditions, the higher the degree of retail competition is, the fewer the ratio of $2 \tilde{\pi}_{R} / \tilde{\pi}_{M}$ is. In fact, as retail competition becomes intensified, both the retailers' and the manufacturer's profits 
TABLE 1: The effect of increasing $b$ values on the optimal decisions and channel efficiency.

\begin{tabular}{ccccccccc}
\hline$b$ & $\eta$ & $\widetilde{w}$ & $\widetilde{z}_{1}=\widetilde{z}_{2}$ & $\widetilde{p}_{1}=\widetilde{p}_{2}$ & $2 \widetilde{\pi}_{R} / \widetilde{\pi}_{M}$ & $\bar{z}_{1}=\bar{z}_{2}$ & $\bar{p}_{1}=\bar{p}_{2}$ & $E_{f}$ \\
\hline \multirow{2}{*}{0.5} & 0.7 & 7.6950 & 0.1607 & 10.9519 & 0.3707 & 0.2691 & 9.2436 & 0.9498 \\
& 0.3 & 7.6950 & 0.0689 & 10.9519 & 0.3705 & 0.2691 & 9.2436 \\
1 & 0.7 & 6.9077 & 0.1351 & 9.8595 & 0.5245 & 0.2117 & 8.9471 \\
& 0.3 & 6.9077 & 0.0579 & 9.8595 & 0.5245 & 0.2117 & 8.9471 & 0.4072 \\
2 & 0.7 & 6.4737 & 0.0988 & 9.1168 & 0.6785 & 0.1486 & 8.6419 & 0.3209 \\
& 0.3 & 6.4737 & 0.0423 & 9.1168 & 0.6792 & 0.1486 & 8.6419 & 0.2730 \\
3 & 0.7 & 6.3210 & 0.0773 & 8.8072 & 0.7572 & 0.1145 & 8.4857 & 0.5978 \\
& 0.3 & 6.3210 & 0.0331 & 8.8072 & 0.7578 & 0.1145 & 8.4857 & 0.2561 \\
4 & 0.7 & 6.2429 & 0.0634 & 8.6338 & 0.8045 & 0.0931 & 8.3907 & 0.5777 \\
& 0.3 & 6.2429 & 0.0272 & 8.6338 & 0.8036 & 0.0931 & 8.3907 & 0.2477 \\
\hline
\end{tabular}

TABLE 2: Optimal solutions of price-only contract by varying the level of risk aversion and retail competition.

\begin{tabular}{|c|c|c|c|c|c|c|c|c|}
\hline$\eta$ & $\gamma$ & $\widetilde{w}$ & $\widetilde{z}_{1}=\widetilde{z}_{2}$ & $\tilde{p}_{1}=\widetilde{p}_{2}$ & $2 \tilde{\pi}_{R} / \tilde{\pi}_{M}$ & $\bar{z}_{1}=\bar{z}_{2}$ & $\bar{p}_{1}=\bar{p}_{2}$ & $E_{f}$ \\
\hline \multirow{5}{*}{0.3} & 0 & 6.4736 & 0.0605 & 9.4232 & 1.0019 & 0.2117 & 8.9471 & 0.2208 \\
\hline & 0.3 & 6.4737 & 0.0536 & 9.3044 & 0.8763 & 0.1877 & 8.8288 & 0.2365 \\
\hline & 0.5 & 6.4737 & 0.0498 & 9.2405 & 0.8092 & 0.1746 & 8.7651 & 0.2470 \\
\hline & 0.7 & 6.4737 & 0.0465 & 9.1857 & 0.7516 & 0.1631 & 8.7105 & 0.2574 \\
\hline & 1 & 6.4737 & 0.0423 & 9.1168 & 0.6792 & 0.1486 & 8.6419 & 0.2730 \\
\hline \multirow{5}{*}{0.5} & 0 & 6.4736 & 0.1008 & 9.4232 & 1.0023 & 0.2117 & 8.9471 & 0.3679 \\
\hline & 0.3 & 6.4737 & 0.0893 & 9.3044 & 0.8770 & 0.1877 & 8.8288 & 0.3941 \\
\hline & 0.5 & 6.4737 & 0.0830 & 9.2405 & 0.8092 & 0.1746 & 8.7651 & 0.4116 \\
\hline & 0.7 & 6.4737 & 0.0775 & 9.1857 & 0.7516 & 0.1631 & 8.7105 & 0.4289 \\
\hline & 1 & 6.4737 & 0.0705 & 9.1168 & 0.6792 & 0.1486 & 8.6419 & 0.4550 \\
\hline \multirow{5}{*}{0.7} & 0 & 6.4736 & 0.1411 & 9.4232 & 1.0024 & 0.2117 & 8.9471 & 0.5150 \\
\hline & 0.3 & 6.4737 & 0.1250 & 9.3044 & 0.8768 & 0.1877 & 8.8288 & 0.5517 \\
\hline & 0.5 & 6.4737 & 0.1162 & 9.2405 & 0.8092 & 0.1746 & 8.7651 & 0.5762 \\
\hline & 0.7 & 6.4737 & 0.1085 & 9.1857 & 0.7516 & 0.1631 & 8.7105 & 0.6005 \\
\hline & 1 & 6.4737 & 0.0988 & 9.1168 & 0.6785 & 0.1486 & 8.6419 & 0.6373 \\
\hline \multirow{5}{*}{0.9} & 0 & 6.4736 & 0.1814 & 9.4232 & 1.0025 & 0.2117 & 8.9471 & 0.6622 \\
\hline & 0.3 & 6.4737 & 0.1607 & 9.3044 & 0.8768 & 0.1877 & 8.8288 & 0.7093 \\
\hline & 0.5 & 6.4737 & 0.1494 & 9.2405 & 0.8092 & 0.1746 & 8.7651 & 0.7409 \\
\hline & 0.7 & 6.4737 & 0.1395 & 9.1857 & 0.7516 & 0.1631 & 8.7105 & 0.7721 \\
\hline & 1 & 6.4737 & 0.1270 & 9.1168 & 0.6787 & 0.1486 & 8.6419 & 0.8193 \\
\hline
\end{tabular}

increase, while the manufacturer's profit increases in $\gamma$ at a higher rate than the retailers' profits. In other words, retail competition can benefit the manufacturer more than the retailers.

Greater $\eta$ means less risk averse according to CVaR definition. By comparing risk aversion and retail competition, when the retailers are less averse to risk, they will set higher selling prices and have larger safety stocks; conversely, increased competition results in lower prices and smaller safety stocks. Such differences lead to opposite trend of the retailers' decisions. As shown in Table 2, when the retailers are more risk averse, the channel efficiency becomes much lower with the fixed $\gamma$. On the other hand, when the competition is more intensified, the channel efficiency becomes much larger with the fixed $\eta$. But how do $\eta$ and $\gamma$ affect channel efficiency? Figure 1 describes the effect of risk aversion $\eta$ on channel efficiency with fixed $b=2$ and $\gamma=0,0.5,1$, respectively. Figure 2 describes the effect of retail competition $\gamma$ on channel efficiency with fixed $b=2$ and $\eta=0.3,0.5,0.7$, respectively. We observe by comparison that the risk aversion level $\eta$ has a more significant influence on the decentralized channel efficiency than retail competition dose. Therefore, in practice, we should not overlook the retailer's attitude to risk.

\section{Conclusions}

This paper investigates the equilibrium decisions of a decentralized supply chain with two risk-averse retailers facing price-sensitive random demand. With the retailers' decisions based on CVaR minimization, we provide a method to prove quasiconcavity, and then, the existence and uniqueness of the optimal pricing-ordering joint decision are proved under the condition of IFR. Further, it is proved that the equilibrium 


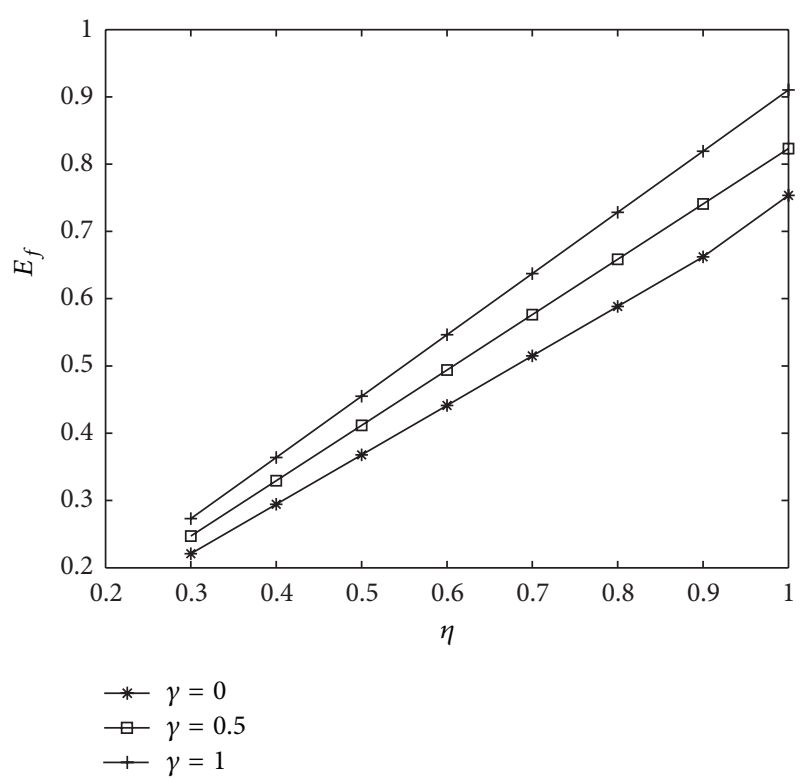

FIGURE 1: The effect of $\eta$ on the channel efficiency.

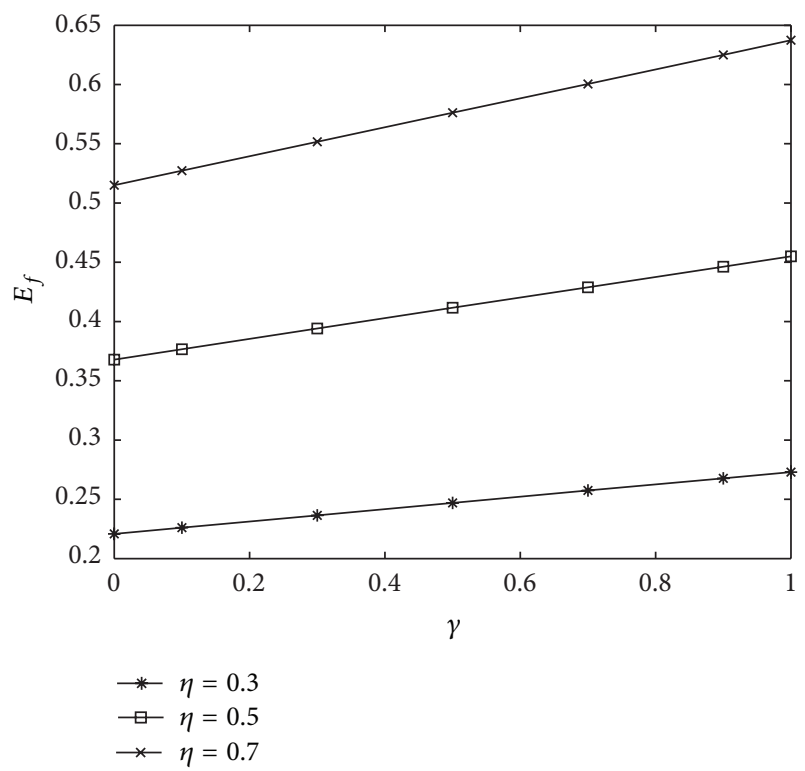

Figure 2: The effect of $\gamma$ on the channel efficiency.

stocking factor and retail price decrease in price sensitivity and retail competition, whereas the equilibrium stocking factor increases in the level of risk aversion.

Our numerical results show that the manufacturer's optimal wholesale price decreases in the price sensitivity factor but keeps constant for any level of risk aversion and retail competition. On the other hand, the retailers' riskaverse attitude has no impact on the optimal retail prices. The more risk-averse retailers will set smaller safety stocks, thereby decreasing the channel efficiency. In contrast, the channel efficiency could be improved when the competition is more intensified. If the retailers are highly averse to risk and not engaged in horizontal price competition, the channel efficiency will approach the minimum value.

Clearly, the results and insights obtained in our paper depend on a specific demand function. The linear and additive demand model is intractable to obtain closed-form solutions. For future work, it would be interesting to examine a more general demand function to obtain the optimal pricing-ordering joint decision under retail competition and risk aversion. RS contract couldnot coordinate a supply chain with two competing retailers in risk-averse environment. Thus, the efforts to explore channel coordination mechanism that leads to near centralized decision could be significative in practice.

Game theory has become an essential tool in the analysis of supply chains with multiple agents. But most of those papers utilize only a few concepts, in particular, the concepts related to Stackelberg and Nash equilibrium. For example, the upstream firm possesses certain power over the downstream firm, and the Stackelberg equilibrium concept has found many applications in many supply chain models. Certain types of games have not yet found application in supply chain. Supply chains today are not limited to one or two tiers and neither are supply and demand simply but are in fact large interconnected and decentralized networks. Thus, it is necessary to study the dynamics of the supply chain as a decentralized interaction between firms. As future work, using evolutionary games $[26,27]$ to analyze supply chain networks is an important research area.

\section{Appendix}

\section{Proofs}

Proof of Lemma 2. First, after some arrangement, we have (5) as follows:

$$
\begin{aligned}
\pi_{i}\left(p_{i}, z_{i}, v_{i}\right) & \\
= & v_{i}-\frac{1}{\eta_{i}} \int_{A}^{z_{i}}\left[v_{i}-y_{i}(p)\left(\phi p_{i} x-\left(w+c_{i}\right) z_{i}\right)\right]^{+} d F(x) \\
& -\frac{1}{\eta_{i}} \int_{z_{i}}^{B}\left[v_{i}-y_{i}(p)\left(\phi p_{i}-w-c_{i}\right) z_{i}\right]^{+} d F(x) .
\end{aligned}
$$

Case 1. $v_{i} \leq y_{i}(p)\left(\phi p_{i} A-\left(w+c_{i}\right) z_{i}\right)$. In this case, $\pi_{i}\left(p_{i}, z_{i}, v_{i}\right)=$ $v_{i}$, and thus,

$$
\frac{\partial \pi_{i}\left(p_{i}, z_{i}, v_{i}\right)}{\partial v_{i}}=1>0
$$

Case 2. $y_{i}(p)\left(\phi p_{i} A-\left(w+c_{i}\right) z_{i}\right)<v_{i} \leq y_{i}(p)\left(\phi p_{i}-w-c_{i}\right) z_{i}$. We can derive that

$$
\begin{aligned}
& \pi_{i}\left(p_{i}, z_{i}, v_{i}\right) \\
& =v_{i}-\frac{1}{\eta_{i}} \int_{A}^{\left(v_{i}+y_{i}(p)\left(w+c_{i}\right) z_{i}\right) / y_{i}(p) \phi p_{i}}\left[v_{i}-y_{i}(p)\left(\phi p_{i} x-\left(w+c_{i}\right) z_{i}\right)\right]^{+} \\
& \times d F(x),
\end{aligned}
$$


and then,

$$
\frac{\partial \pi_{i}\left(p_{i}, z_{i}, v_{i}\right)}{\partial v_{i}}=1-\frac{1}{\eta_{i}} F\left(\frac{v_{i}+y_{i}(p)\left(w+c_{i}\right) z_{i}}{y_{i}(p) \phi p_{i}}\right) .
$$

Thus,

$$
\begin{gathered}
\left.\frac{\partial \pi_{i}\left(p_{i}, z_{i}, v_{i}\right)}{\partial v_{i}}\right|_{v_{i}=y_{i}(p)\left(\phi p_{i} A-\left(w+c_{i}\right) z_{i}\right)}=1, \\
\left.\frac{\partial \pi_{i}\left(p_{i}, z_{i}, v_{i}\right)}{\partial v_{i}}\right|_{y_{i}(p)\left(\phi p_{i}-w-c_{i}\right) z_{i}}=1-\frac{F\left(z_{i}\right)}{\eta_{i}} .
\end{gathered}
$$

Case 3. $v_{i}>y_{i}(p)\left(\phi p_{i}-w-c_{i}\right) z_{i}$. We have

$$
\frac{\partial \pi_{i}\left(p_{i}, z_{i}, v_{i}\right)}{\partial v_{i}}=1-\frac{1}{\eta_{i}}<0 .
$$

Let $v_{i}^{*}\left(p_{i}, z_{i}\right)=\arg \max \pi_{i}\left(p_{i}, z_{i}, v_{i}\right)$ be the optimal solution for fixed $p_{i}$ and $z_{i}$. Combining Cases 1-3, we obtain

$$
\begin{array}{r}
v_{i}^{*}\left(p_{i}, z_{i}\right) \in\left[y_{i}(p)\left(\phi p_{i} A-\left(w+c_{i}\right) z_{i}\right),\right. \\
\left.y_{i}(p)\left(\phi p_{i}-w-c_{i}\right) z_{i}\right] .
\end{array}
$$

If $z_{i}<F^{-1}\left(\eta_{i}\right)$, then

$$
v_{i}^{*}\left(p_{i}, z_{i}\right)=y_{i}(p)\left(\phi p_{i}-w-c_{i}\right) z_{i} .
$$

If $z_{i} \geq F^{-1}\left(\eta_{i}\right)$, then

$$
v_{i}^{*}\left(p_{i}, z_{i}\right)=y_{i}(p)\left[F^{-1}\left(\eta_{i}\right) \phi p_{i}-\left(w+c_{i}\right) z_{i}\right] .
$$

We thus have

$$
\begin{aligned}
\pi_{i}\left(p_{i}, z_{i}, v_{i}^{*}\right)= & y_{i}(p)\left[F^{-1}\left(\eta_{i}\right) \phi p_{i}-\left(w+c_{i}\right) z_{i}\right] \\
& -\frac{y_{i}(p)}{\eta_{i}} \int_{A}^{F^{-1}\left(\eta_{i}\right)} \phi p_{i}\left(F^{-1}\left(\eta_{i}\right)-x\right) d F(x) .
\end{aligned}
$$

Notice that $\partial \pi_{i}\left(p_{i}, z_{i}, v_{i}^{*}\right) / \partial z_{i}=-y_{i}(p)\left(w+c_{i}\right)<0$. Therefore, when $z_{i}=F^{-1}\left(\eta_{i}\right), \pi_{i}\left(p_{i}, z_{i}, v_{i}^{*}\right)$ maximize.

Proof of Proposition 4. First, for any given $z_{i}\left(A \leq z_{i}<\right.$ $F^{-1}\left(\eta_{i}\right)$ ), we take the partial derivative of (8) with respect to $p_{i}$ and get

$$
\begin{aligned}
\frac{\partial \pi_{\eta_{i}}\left(p_{i}, z_{i}\right)}{\partial p_{i}}= & y_{i}(p) \\
\times & {\left[(b+\gamma)\left(w+c_{i}\right) z_{i}+\phi\left(z_{i}-\frac{1}{\eta_{i}} \Lambda\left(z_{i}\right)\right)\right.} \\
& \left.\quad-(b+\gamma) \phi p_{i}\left(z_{i}-\frac{1}{\eta_{i}} \Lambda\left(z_{i}\right)\right)\right] .
\end{aligned}
$$

Since $y_{i}(p)>0, \partial \pi_{\eta_{i}}\left(p_{i}, z_{i}\right) / \partial p_{i}=0$ implies that

$$
p_{i}^{*}\left(z_{i}\right)=\frac{1}{b+\gamma}+\frac{w+c_{i}}{\phi} \frac{\eta_{i} z_{i}}{\eta_{i} z_{i}-\Lambda\left(z_{i}\right)},
$$

which is (9). Meanwhile, for any given $z_{i}, \partial \pi_{\eta_{i}}\left(p_{i}, z_{i}\right) / \partial p_{i}>0$ for all $p_{i}<p_{i}^{*}\left(z_{i}\right)$ and $\partial \pi_{\eta_{i}}\left(p_{i}, z_{i}\right) / \partial p_{i}<0$ for all $p_{i}>p_{i}^{*}\left(z_{i}\right)$. So, $p_{i}^{*}\left(z_{i}\right)$ is the unique maximizer of $\pi_{\eta_{i}}\left(p_{i}, z_{i}\right)$.

Next, we want to derive $z_{i}^{*}$, which maximizes $\pi_{\eta_{i}}\left(p_{i}^{*}\left(z_{i}\right), z_{i}\right)$. By the chain rule, we have

$$
\begin{aligned}
\frac{d \pi_{\eta_{i}}\left(p_{i}^{*}\left(z_{i}\right), z_{i}\right)}{d z_{i}}= & \frac{\partial \pi_{\eta_{i}}\left(p_{i}^{*}\left(z_{i}\right), z_{i}\right)}{\partial p_{i}} \frac{d p_{i}^{*}\left(z_{i}\right)}{d z_{i}} \\
& +\frac{\partial \pi_{\eta_{i}}\left(p_{i}^{*}\left(z_{i}\right), z_{i}\right)}{\partial z_{i}} .
\end{aligned}
$$

Since $p_{i}^{*}\left(z_{i}\right)$ is the unique maximizer of $\pi_{\eta_{i}}\left(p_{i}, z_{i}\right)$, $\partial \pi_{\eta_{i}}\left(p_{i}^{*}\left(z_{i}\right), z_{i}\right) / \partial p_{i}=0$, thus

$$
\frac{d \pi_{\eta_{i}}\left(p_{i}^{*}\left(z_{i}\right), z_{i}\right)}{d z_{i}}=\frac{y_{i}\left(p^{*}\right)}{(b+\gamma)\left(\eta_{i} z_{i}-\Lambda\left(z_{i}\right)\right)} g\left(z_{i}\right),
$$

where

$$
\begin{aligned}
g\left(z_{i}\right)= & \left(\eta_{i}-F\left(z_{i}\right)\right) \\
& \times\left[\phi\left(z_{i}-\frac{1}{\eta_{i}} \Lambda\left(z_{i}\right)\right)+(b+\gamma)\left(w+c_{i}\right) z_{i}\right] \\
& -(b+\gamma) \eta_{i}\left(w+c_{i}\right)\left(z_{i}-\frac{1}{\eta_{i}} \Lambda\left(z_{i}\right)\right) .
\end{aligned}
$$

Because the first factor in the above expression is always positive, first-order condition requires that the optimal $z_{i}^{*}$ satisfies $g\left(z_{i}^{*}\right)=0$, which gives us (10).

Such a $z_{i}^{*}$ always exists in the support interval $\left[A, F^{-1}\left(\eta_{i}\right)\right)$ of $\varepsilon$, since $g\left(z_{i}\right)$ is continuous in $\left[A, F^{-1}\left(\eta_{i}\right)\right), g(A)=\eta_{i} \phi A>$ 0 , and $g\left(F^{-1}\left(\eta_{i}\right)\right)<0$. To verify the uniqueness of $z_{i}^{*}$, we have

$$
\begin{aligned}
g^{\prime}\left(z_{i}\right)=\left(\eta_{i}-F\left(z_{i}\right)\right) & \\
\times & \left\{\frac{\phi}{\eta_{i}}\left(\eta_{i}-F\left(z_{i}\right)\right)-h_{\eta_{i}}\left(z_{i}\right)\right. \\
& \left.\times\left[\phi\left(z_{i}-\frac{1}{\eta_{i}} \Lambda\left(z_{i}\right)\right)+(b+\gamma)\left(w+c_{i}\right) z_{i}\right]\right\}, \\
g^{\prime \prime}\left(z_{i}\right)=- & h_{\eta_{i}}\left(z_{i}\right) g^{\prime}\left(z_{i}\right)+\left(\eta_{i}-F\left(z_{i}\right)\right) \\
\times & \left\{-\frac{\phi}{\eta_{i}} f\left(z_{i}\right)-h_{\eta_{i}}^{\prime}\left(z_{i}\right)\right. \\
& \times\left[\phi\left(z_{i}-\frac{1}{\eta_{i}} \Lambda\left(z_{i}\right)\right)+(b+\gamma)\left(w+c_{i}\right) z_{i}\right] \\
& -h_{\eta_{i}}\left(z_{i}\right)\left[\phi\left(1-\frac{1}{\eta_{i}} F\left(z_{i}\right)\right)\right. \\
& \left.\left.+(b+\gamma)\left(w+c_{i}\right)\right]\right\} .
\end{aligned}
$$

According to Assumption 1 and Lemma 3, we have $h_{\eta_{i}}^{\prime}\left(z_{i}\right)>0$. Thus, $g^{\prime \prime}\left(z_{i}\right)<0$ at $g^{\prime}\left(z_{i}\right)=0$, which implies that 
$g\left(z_{i}\right)$ is a unimodal function in $\left[A, F^{-1}\left(\eta_{i}\right)\right)$, which guarantees the uniqueness of $z_{i}^{*}$.

Proof of Lemma 5. First, after some arrangement, we have

$$
G(z)=\frac{\eta(z F(z)-\Lambda(z))}{(\eta-F(z))(\eta z-\Lambda(z))} .
$$

Next, we take the derivative of $G(z)$ with respect to $z$ and thus get

$$
\begin{aligned}
& \frac{d G(z)}{d z} \\
& =\frac{\eta}{[(\eta-F(z))(\eta z-\Lambda(z))]^{2}} \\
& \quad \times\left\{f(z)[\eta z-\Lambda(z)]^{2}-[\eta-F(z)]^{2}[z F(z)-\Lambda(z)]\right\} .
\end{aligned}
$$

Since the $\eta$-failure rate of probability distribution is defined as $h_{\eta}(z)=f(z) /[\eta-F(z)]$, equivalently, we have $f(z)=$ $h_{\eta}(z)[\eta-F(z)]$. Then, substitute $h_{\eta}(z)[\eta-F(z)]$ for $f(z)$ in the above expression and put forward $[\eta-F(z)]$, and now, it can be rewritten as

$$
\frac{d G(z)}{d z}=\frac{\eta}{(\eta-F(z))[\eta z-\Lambda(z)]^{2}} T(z),
$$

where $T(z)=h_{\eta}(z)[\eta z-\Lambda(z)]^{2}-(\eta-F(z))[z F(z)-\Lambda(z)]$.

The first factor in the above expression is always positive. So, if $T(z) \geq 0$ for any $z \in\left[A, F^{-1}\left(\eta_{i}\right)\right), G(z)$ is increasing in $z$. To show that $T(z) \geq 0$ for any $z \in\left[A, F^{-1}\left(\eta_{i}\right)\right)$, we take the derivative of $T(z)$ with respect to $z$ and get

$$
\begin{aligned}
\frac{d T(z)}{d z}= & h_{\eta}^{\prime}(z)[\eta z-\Lambda(z)]^{2} \\
& +2 f(z)[z F(z)-\Lambda(z)]+f(z)[\eta z-\Lambda(z)] .
\end{aligned}
$$

Since $h_{\eta}^{\prime}(z), f(z), \eta z-\Lambda(z)$, and $z F(z)-\Lambda(z)$ in the above expression are all positive for any $z \in\left[A, F^{-1}\left(\eta_{i}\right)\right)$, we have $d T(z) / d z>0$, which indicates that $T(z)$ is increasing in $z$. Hence, $T(z) \geq T(A)=h_{\eta}(A)(\eta A)^{2} \geq 0$. Therefore, $d G(z) / d z \geq 0$, meaning that $G(z)$ is increasing in $z$.

Proof of Proposition 6. (1) $\phi /(b+\gamma)\left(w+c_{i}\right)$ is decreasing in $b$; so, $G\left(z_{i}^{*}\right)$ of (12) is decreasing in $b$. By Lemma 5 , we have $z_{i}^{*}$ decreases in $b$.

(2) We take the derivative of $p_{i}^{*}\left(z_{i}\right)$ with respect to $b$ and thus get

$$
\frac{d p_{i}^{*}}{d b}=-\frac{1}{(b+\gamma)^{2}}+\frac{\left(w+c_{i}\right) \eta_{i}}{\phi} \frac{z_{i}^{*} F\left(z_{i}^{*}\right)-\Lambda\left(z_{i}^{*}\right)}{\left[\eta_{i} z_{i}^{*}-\Lambda\left(z_{i}^{*}\right)\right]^{2}} \frac{d z_{i}^{*}}{d b} .
$$

Since $z_{i}^{*} F\left(z_{i}^{*}\right)-\Lambda\left(z_{i}^{*}\right)>0$ and $d z_{i}^{*} / d b<0$, we have $d p_{i}^{*} / d b<$ 0 .

Remark. Substituting $b$ with $\gamma$, we have $z_{i}^{*}$ and $p_{i}^{*}$ decrease in $\gamma$.
(3) First, after some arrangement, (10) becomes

$$
\begin{aligned}
R\left(z_{i}^{*}\right)= & \left(\eta_{i}-F\left(z_{i}^{*}\right)\right) \\
& \times\left[\phi\left(z_{i}^{*}-\frac{1}{\eta_{i}} \Lambda\left(z_{i}^{*}\right)\right)+(b+\gamma) z_{i}^{*}\left(w+c_{i}\right)\right] \\
& -(b+\gamma) \eta_{i}\left(w+c_{i}\right)\left(z_{i}^{*}-\frac{1}{\eta_{i}} \Lambda\left(z_{i}^{*}\right)\right) \\
= & 0 .
\end{aligned}
$$

By the derivative rule of implicit function, we get

$$
\frac{d z_{i}^{*}}{d \eta_{i}}=-\frac{\left(\partial R / \partial \eta_{i}\right)}{\left(\partial R / \partial z_{i}^{*}\right)}
$$

where $\partial R / \partial \eta_{i}=\phi\left(z_{i}^{*}-\left(1 / \eta_{i}\right) \Lambda\left(z_{i}^{*}\right)\right)+\left(\eta_{i}-F\left(z_{i}^{*}\right)\right) \phi(1 /$ $\left.\eta_{i}^{2}\right) \Lambda\left(z_{i}^{*}\right)>0$.

$R(A)=\eta_{i} \phi A>0$, and $R\left(F^{-1}\left(\eta_{i}\right)\right)<0, z_{i}^{*}$ is unique solution of $R\left(z_{i}^{*}\right)=0$; thus, $\partial R / \partial z_{i}^{*}<0$. Therefore, $d z_{i}^{*} / d \eta_{i}>$ 0 .

\section{Acknowledgment}

This work is partially supported by the Natural Science Foundation of Shandong Province, China (no. ZR2010GM006).

\section{References}

[1] N. C. Petruzzi and M. Dada, "Pricing and the newsvendor problem: a review with extensions," Operations Research, vol. 47, no. 2, pp. 183-194, 1999.

[2] L. Yao, Y. H. Chen, and H. M. Yan, "The newsvendor problem with pricing: extensions," International Journal of Management Science and Engineering Management, vol. 1, no. 1, pp. 3-16, 2006.

[3] A. Kocabiyıkoğlu and I. Popescu, "An elasticity approach to the newsvendor with price-sensitive demand," Operations Research, vol. 59, no. 2, pp. 301-312, 2011.

[4] X. Xu, X. Cai, and Y. Chen, "Unimodality of price-setting newsvendor's objective function with multiplicative demand and its applications," International Journal of Production Economics, vol. 133, no. 2, pp. 653-661, 2011.

[5] K. Pan, K. K. Lai, S. C. H. Leung, and D. Xiao, "Revenue-sharing versus wholesale price mechanisms under different channel power structures," European Journal of Operational Research, vol. 203, no. 2, pp. 532-538, 2010.

[6] Z. Yao, S. C. H. Leung, and K. K. Lai, "Manufacturer's revenuesharing contract and retail competition," European Journal of Operational Research, vol. 186, no. 2, pp. 637-651, 2008.

[7] E. Adida and N. Ratisoontorn, "Consignment contracts with retail competition," European Journal of Operational Research, vol. 215, no. 1, pp. 136-148, 2011.

[8] F. Bernstein and A. Federgruen, "Decentralized supply chains with competing retailers under demand uncertainty," Management Science, vol. 51, no. 1, pp. 18-29, 2005.

[9] L. Eeckhoudt, C. Gollier, and H. Schlesinger, "Risk averse (and prudent) newsboy," Management Science, vol. 41, no. 5, pp. 786794, 1995. 
[10] V. Agrawal and S. Seshadri, "Impact of uncertainty and risk aversion on price and order quantity in the newsvendor problem," Manufacturing \& Service Operations Management, vol. 2, no. 4, pp. 410-423, 2000.

[11] T.-M. Choi, D. Li, H. Yan, and C.-H. Chiu, "Channel coordination in supply chains with agents having mean-variance objectives," Omega, vol. 36, no. 4, pp. 565-576, 2008.

[12] X. Gan, S. P. Sethi, and H. Yan, "Channel coordination with a risk-neutral supplier and a downside-risk-averse retailer," Production and Operations Management, vol. 14, no. 1, pp. 8089, 2005.

[13] J. Wu, S. Wang, X. Chao, C. T. Ng, and T. C. E. Cheng, "Impact of risk aversion on optimal decisions in supply contracts," International Journal of Production Economics, vol. 128, no. 2, pp. 569-576, 2010.

[14] Y. Chen, M. Xu, and Z. G. Zhang, "A risk-averse newsvendor model under the CVaR criterion," Operations Research, vol. 57, no. 4, pp. 1040-1044, 2009.

[15] C.-C. Hsieh and Y.-T. Lu, "Manufacturer's return policy in a two-stage supply chain with two risk-averse retailers and random demand," European Journal of Operational Research, vol. 207, no. 1, pp. 514-523, 2010.

[16] Y. Wang, L. Jiang, and Z.-J. Shen, "Channel performance under consignment contract with revenue sharing," Management Science, vol. 50, no. 1, pp. 34-47, 2004.

[17] Y. Song, S. Ray, and S. Li, "Structural properties of buyback contracts for price-setting newsvendors," Manufacturing \& Service Operations Management, vol. 10, no. 1, pp. 1-18, 2008.

[18] M. A. Lariviere, "A note on probability distributions with increasing generalized failure rates," Operations Research, vol. 54, no. 3, pp. 602-604, 2006.

[19] J. Ru and Y. Wang, "Consignment contracting: who should control inventory in the supply chain?" European Journal of Operational Research, vol. 201, no. 3, pp. 760-769, 2010.

[20] C. S. Tang and R. Yin, "Joint ordering and pricing strategies for managing substitutable products," Production and Operations Management, vol. 16, no. 1, pp. 138-153, 2007.

[21] R. R. Chen and P. Roma, "Group buying of competing retailers," Production and Operations Management, vol. 20, no. 2, pp. 181197, 2011.

[22] S. C. Choi, "Price competition in a duopoly common retailer channel," Journal of Retailing, vol. 72, no. 2, pp. 117-134, 1996.

[23] X. Zhao and D. R. Atkins, "Newsvendors under simultaneous price and inventory competition," Manufacturing \& Service Operations Management, vol. 10, no. 3, pp. 539-546, 2008.

[24] R. T. Rockafellar and S. Uryasev, "Optimization of conditional value-at-risk," Journal of Risk, vol. 2, no. 3, pp. 21-42, 2000.

[25] R. T. Rockafellar and S. Uryasev, "Conditional value-at-risk for general loss distributions," Journal of Banking and Finance, vol. 26, no. 7, pp. 1443-1471, 2002.

[26] M. Perc, J. Gómez-Gardeñes, A. Szolnoki, L. M. Floría, and Y. Moreno, "Evolutionary dynamics of group interactionson structured populations: a review," Interface, vol. 10, no. 80, pp. $1-18,2013$.

[27] Z. Wang, A. Szolnoki, and M. Perc, "Interdependent network reciprocity in evolutionary games," Scientific Reports, pp. 1-7, 2013. 


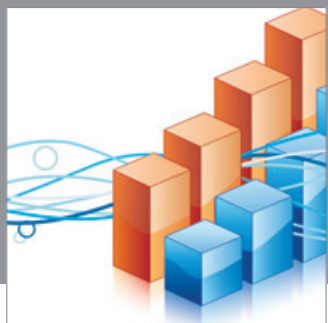

Advances in

Operations Research

mansans

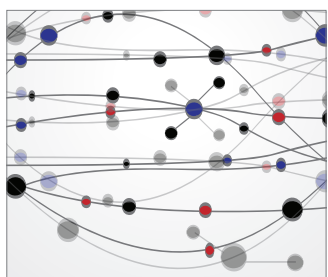

The Scientific World Journal
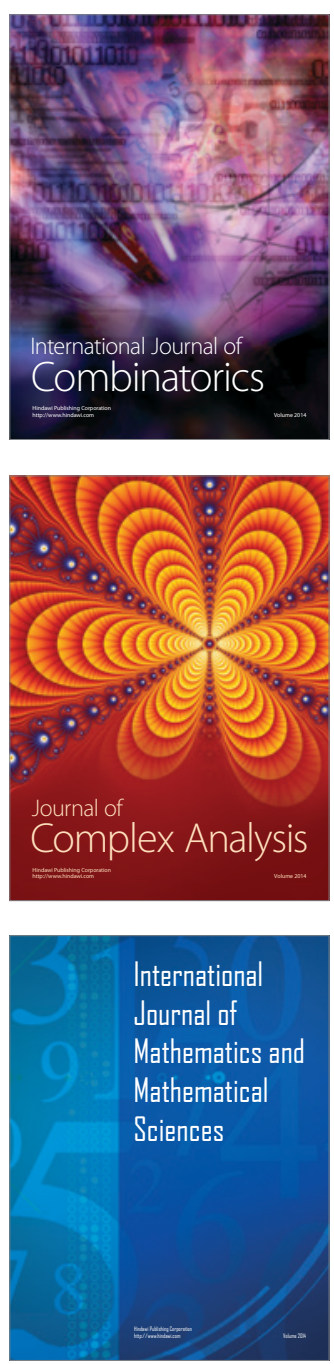
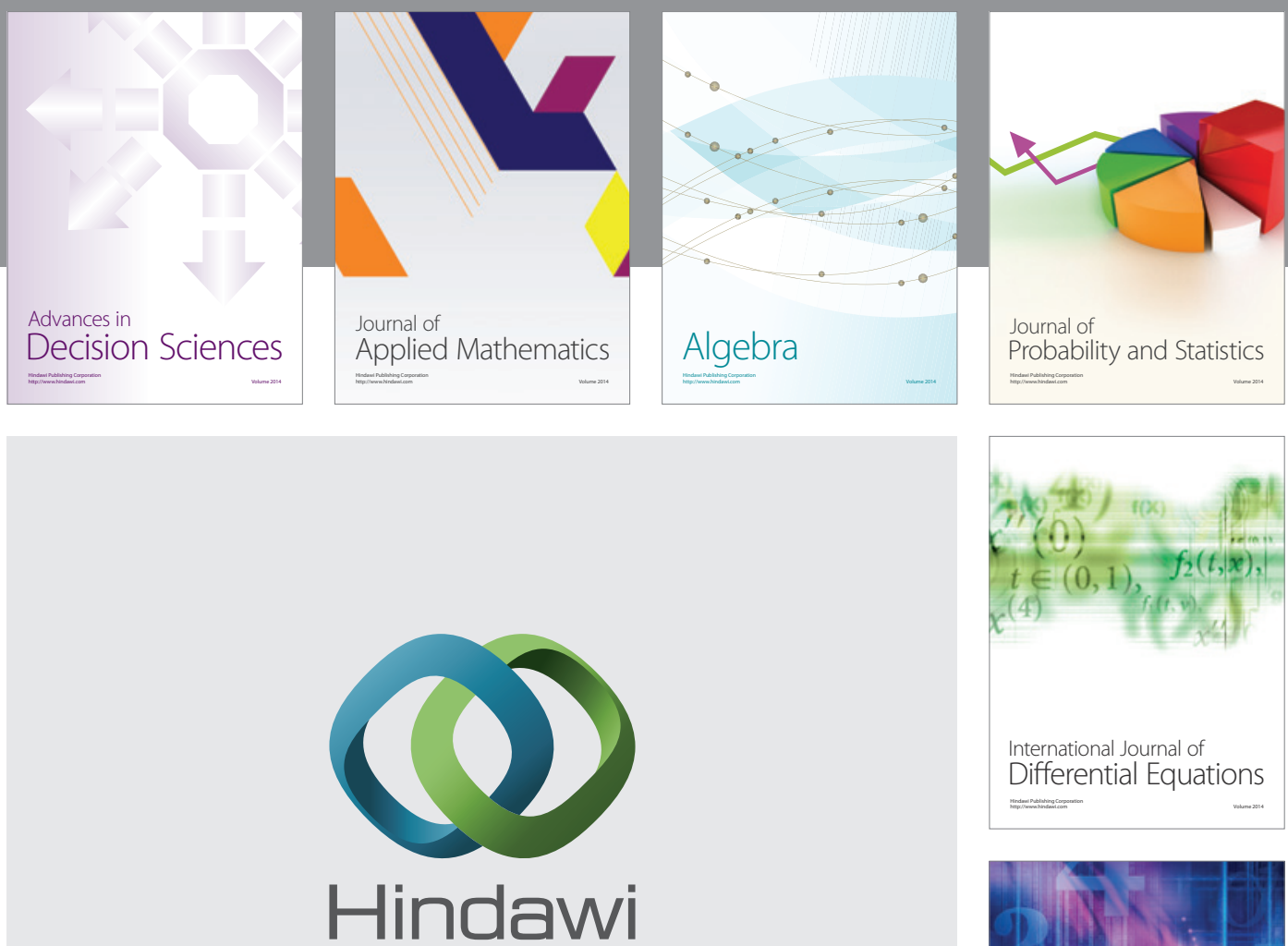

Submit your manuscripts at http://www.hindawi.com
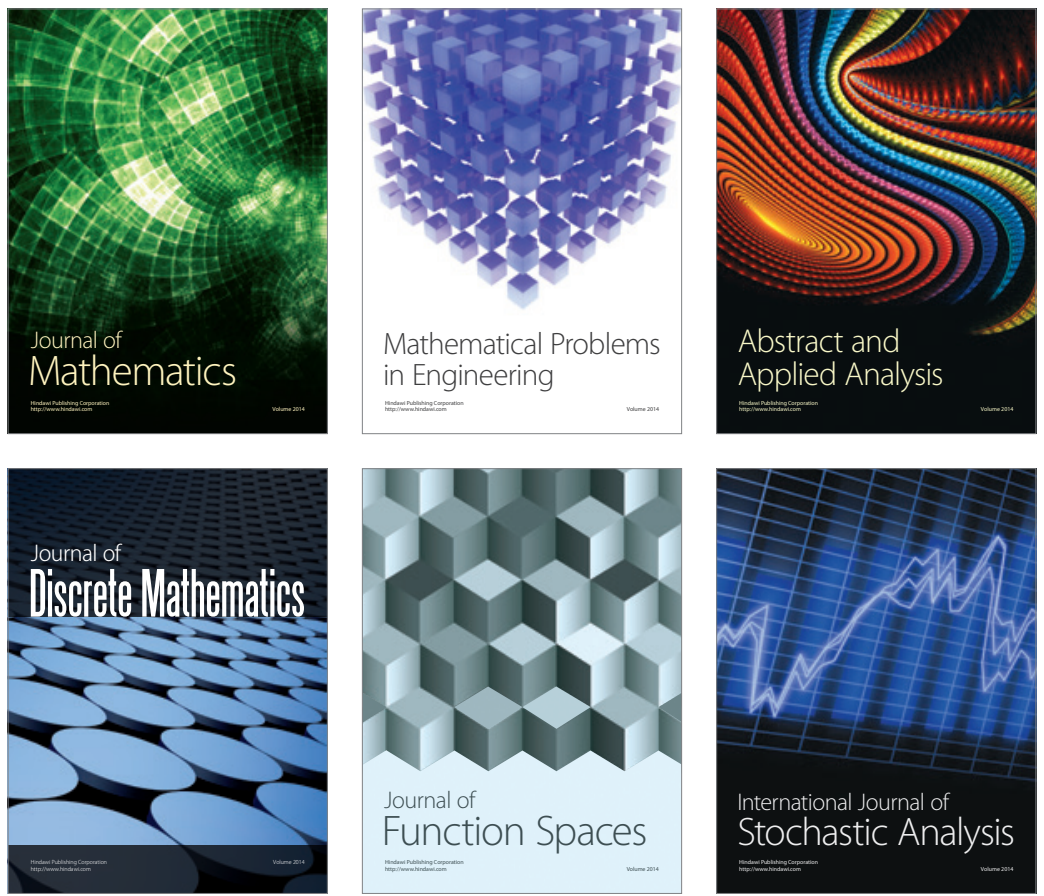

Journal of

Function Spaces

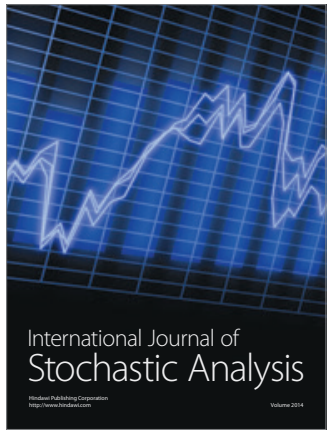

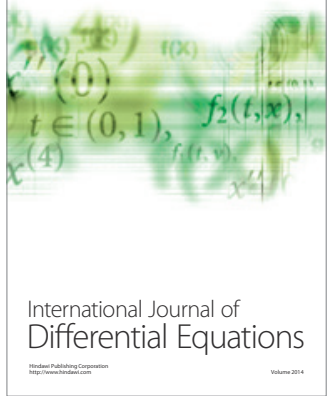
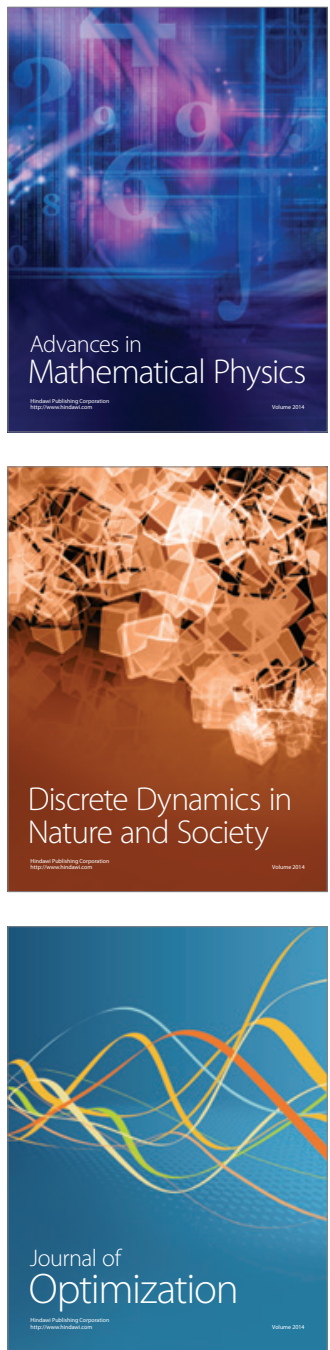